\title{
OBSTRUKCINĖS MIEGO APNĖJOS GYDYMAS POLIEŽUVINIO NERVO STIMULIACIJOS METODU
}

\author{
Liveta Sereikaitė ${ }^{1}$, Monika Jasinskaitė ${ }^{1}$, Simas Stiklioraitis ${ }^{1}$, Živilè Undzènaitė ${ }^{2}$ \\ ${ }^{1}$ Lietuvos sveikatos mokslu universiteto Medicinos akademijos Medicinos fakultetas, \\ ${ }^{2}$ Lietuvos sveikatos moksly universiteto ligonine, Ausu, nosies ir gerklès ligu klinika
}

Raktažodžiai: poliežuvinio nervo stimuliacija, OMA (obstrukcinè miego apnèja).

\begin{abstract}
Santrauka
Obstrukcinè miego apnèja yra klinikinè būklè, kelianti grèsmę žmogaus sveikatai. Nuolatinio teigiamojo slègio ventiliacija yra pagrindinis šios patologijos gydymo būdas, duodantis teigiamus rezultatus, tačiau jo netinkamas taikymas mažina gydymo efektyvumą. Plačiai žinomos ịvairios alternatyvos, tokios kaip viršutinių kvẻpavimo takų chirurginès operacijos, pakeičia tik anatomini obstrukcinès miego apnèjos komponentą. Per pastaruosius keletą dešimtmečių nemažai klinikinių tyrimų parodè, jog poliežuvinio nervo stimuliacija, kuri koreguoja anatominị ir neuromuskulini patologijos komponentus, yra pažangus šios ligos gydymo pasirinkimas.
\end{abstract}

\section{İvadas}

OMA yra lètinè liga, kuriai būdingi pasikartojantys kvèpavimo sustojimai miego metu, lydimi epizodinès hipoksijos [1]. Ligos sunkumas matuojamas naudojant apnejų-hipopnèjų indeksą (toliau - AHI). AHI parodo vidutini apnejjų ir hipopnejjų skaičiu per valandą miego. OMA nustatoma, kai AHI yra $\geq 5$ ịvykiai/val., OMA sindromas - kai AHI $\geq 5$ ivykiai/val. ir mieguistumas dienos metu [2]. OMA paplitimas nèra tiksliai žinomas. Tyrimų duomenimis, jis skiriasi dèl diagnostikos kriterijų ịvairovès. Naujesniuose tyrimuose OMA paplitimas JAV siejamas su padidejusiu nutukimu ir pasireiškia apie 10 proc. $30-49$ metų vyrų ir 3 proc. to paties amžiaus moteru [3]. OMA ne tik blogina sergančiųų ir jų artimujų gyvenimo kokybę, bet didina visuomenès mirtingumo riziką, susijusią su nelaimingais atsitikimais (ypač mieguistumas vairuojant) [4], sergamumu širdies ir kraujagyslių ligomis [5], reikšmingai prisidedama prie neurokognityvinių, metaboliniu bei onkologinių ligų atsiradimo ir progresavimo [6-11]. Nuolatinio teigiamojo slègio aparatas (toliau - CPAP) išlieka pagrindinė OMA gydymo priemonè, efektyviai mažinanti AHI [12]. Nepakankamas CPAP naudojimas smarkiai sumažino šios priemonès efektyvumą [13]. Nepaisant edukacijos ir technologinès pažangos, gydymas CPAP išlieka sudètingas nemažai daliai pacientų, sergančių OMA [14]. CPAP alternatyvos yra elgesio modifikacija (pvz.: kūno svorio mažinimas, padèties keitimo strategijos, alkoholio vartojimo nutraukimas, viršutinių kvėpavimo takų raumenų pratimai), intraoraliniai (pvz., neigiamo slègio, žandikaulio ir liežuvio pakèlimo) prietaisai ir ịvairios chirurginès minkštujų audinių pašalinimo procedūros (pvz., tonzilektomija, uvulopalatofaringoplastika), ryklès išplètimas (pvz., šoninė faringoplastika) ir poliežuvinio kaulo pakabinimo operacija ar dviejų žandikaulių ortognatinè operacija [15]. Pastaraisiais metais poliežuvinio nervo ( . hypoglossus) stimuliacija tapo perspektyviu terapiniu metodu, palengvinančiu neuromotorinio valdymo sutrikimus miego metu. Šioje apžvalgoje nagrinèjami šio terapinio būdo klinikiniai rezultatai ir būsimos taikymo kryptys.

Darbo tikslas - apžvelgti sergančiujų miego apnejja viršutinių kvèpavimo takų fiziologiją, pacientų atranką poliežuvinio nervo stimuliatoriaus implantacijos operacijai, jos metodus bei rezultatus.

\section{Tyrimo objektas ir metodika}

Mokslinès literatūros šaltinių ieškota PubMed, Cohrane, ScienceDirect, Medscape duomenų bazėse. Apžvalgai naudoti 2015-2020 metais spausdinti straipsniai anglų kalba, atitinkantys tyrimo temą.

\section{Tyrimo rezultatai}

Obstrukcinès miego apnėjos patofiziologija. Obstrukcinè miego apnèja yra sudètinès daugiaveiksnès etiologijos liga. Ne tik anatominiai veiksniai (pvz., skeleto struktūra, ryklès ir viršutinių kvėpavimo takų anatomija), bet ir neuroraumeninis kvejpavimo valdymas miego metu yra svarbus OMA patofiziologijoje (pvz., ryklès dilatatorių toninis 
aktyvumas) [16,17]. Smakrinis liežuvio raumuo (musculus genioglossus, toliau $-m$. genioglossus) yra vienas iš svarbiausių viršutinių kvejpavimo takų praeinamumo dilatatorių miego metu. Pagrindinès šio raumens funkcijos yra liežuvio suplokštinimas ir iškišimas. Raumenị inervuoja vidurinè $n$. hypoglossus šaka, mažindama raumenų aktyvumą iškvèpimo ir didindama ikvépimo metu [18]. Elektromiografija pabudimo metu registruoja padidèjusi $m$. genioglossus aktyvumą, lyginant su sveikujų kontrolinèmis grupėmis [19]. Ilgą laiką šis reiškinys buvo apibūdinamas kaip sergančiujų OMA susiaurejusių kvejpavimo takų bei padidejjusios kolapso rizikos kompensavimo mechanizmas. Naujausi tyrimai parodè, kad miego metu atviri kvèpavimo takai būna dèl ryklès neuroraumeninio aktyvumo, o jo pažeidimas lemia viršutinių kvẻpavimo takų obstrukciją [20,21]. 16 pacientų buvo tirtas poliežuvinio nervo laidumas, 75 proc. iš jų buvo stebimas uždelstas distalinis latentinis laikotarpis, 100 proc. - maža motorinè amplitudè, lyginant su norma. Šis tyrimas pagrịstų viršutinių kvépavimo takų neuroraumeninio aktyvumo svarbą OMA patogenezéje [22]. Pereinant nuo pabudimo būsenos i miego, mažeja $m$. genioglossus aktyvumas ir didèja viršutinių kvėpavimo takų pasipriešinimas [23]. Miegant $m$. genioglossus aktyvumas OMA pacientams sumažèja gerokai sparčiau, nei sveikiems asmenims ir sukelia viršutinių kvejpavimo takų obstrukciją [24]. Sveikiems žmonėms miegant, elektromiografinio tyrimo metu nustatomas didejantis $m$. genioglossus aktyvumas, kaip atsakas ị neigiamą intraluminalinị slègị. Sergantiems OMA, tokio aktyvumo didèjimo nenustatyta $[16,25]$. N. hypoglossus stimuliacija siekiama padidinti dilatacinių raumenų tonusą ir sumažinti neuroraumeninès kontrolès sutrikimus.

Stimuliuojant $n$. hypoglossus proksimalinį kamieną ir vidurinę šaką, stebimas sumažèjęs ryklès kolapsas bei padidèjęs $m$. genioglossus atsakas ị neigiamą kvėpavimo takų slégi. $N$. hypoglossus inervuoja $m$. genioglossus, kuris yra ryklès dilatatorius ir gali apsaugoti nuo liežuvio prolapso i ryklę, kuris lemtų viršutinių kvėpavimo takų obstrukciją [19-27].

\section{Pacientų atranka}

Viršutinių kvẻpavimo takų kolapsavimas. Gausūs tyrimų duomenys rodo reikšmingą viršutinių kvėpavimo takų kolapsavimo poveikį miego apnejjos patogenezei ir atsakui ị gydymą. Miego metu kvèpavimo takų slègiui didejjant link atmosferos slėgio ar daugiau, pasireiškia kvėpavimo takų obstrukcija [28]. Pacientams, kurių kvėpavimo takų slègis miego metu yra gerokai didesnis už atmosferos slègị, elektrinè stimuliacija gali būti nepakankama ịveikti anatominị krūvị ir(ar) neuroraumeninius veiksnius. Tokių asmenų ryklè yra labiau linkusi i obstrukciją. Ši informacija svarbi, parenkant pacientus poliežuvinio nervo stimuliacijai

Ryklès forma. Atsakas ị stimuliaciją gali priklausyti nuo ryklès liumeno formos retropalataliniame ir retroglosiniame segmentuose bei liežuvio dydžio. Profesorius James C. Leiter [40] teigia, jog elipsès formos liežuvis bei jo didžioji ašis, esanti lateralinėje, o mažoji - priekinejje-užpakalinejje kryptyse, labiau lemia ryklès liumeno praeinamumą. Tokiu atveju, liežuvio protruzija lemia didesni ryklès kanalo praeinamumą, nei cirkuliaraus ryklès kolapso atveju. Šią hipotezę patvirtina faktas, jog taikant stimuliaciją šiai žmonių grupei, buvo gauti teigiami rezultatai [36]. Atsakas gali būti silpnesnis pacientams, turintiems platų minkštajị gomurị [41], o tai rodo, jog liežuvio bei kaulinès struktūros įvertinimas yra svarbus pacientų atrankos kriterijus.

\section{Poliežuvinio nervo stimuliatoriaus implantacija}

Tyrejjai pateikia įrodymų dèl $n$. hypoglossus stimuliacijos veiksmingumo. Šią $n$. hypoglossus stimuliuojančią sistemą sudaro keli pagrindiniai komponentai. Impulsų generatorius (toliau - IIG) implantuojamas chirurginiu būdu ị infraklavikulinę poodinę poraktikaulinę kišenę, esančią prieš didijj krūtinès raumenị. IIG perduoda elektrinius impulsus i n. hypoglossus. Stimuliacijos modeliai apibrèžiami pagal individualių impulsų plotị, dažnị ir amplitudę, kurie sugeneruojami per tam tikrą laiką. Pliūpsniai perduodami manžetès elektrodu, apvyniotu aplink n. hypoglossus. Jutimų ir stimuliacijos laidai implantuojami po oda nuo IIG link apatiniu šonkaulių ir $n$. hypoglossus. Stimuliuojančios atviros kilpos sistemos skatina stimuliaciją, nepriklausomai nuo kvėpavimo fazès [29]. Šiuo metu taikomos $n$. hypoglossus stimuliavimo sistemos: stimuliacijos laidas yra distaliai pritvirtintas prie n. hypoglossus medialinès šakos. Stimuliuojantys impulsai perduodami elektrodais, sinchronizuotais su ventiliacija, kurią nustato jutiklis.

Kita sistema: implantuojama šešių elektrodų detalè, apipinta aplink $n$. hypoglossus pagrindinị kamieną. Impulsų generatoriai yra abiejose sistemose ipsilaterinejje infraklavikulinèje poodinèje kišenejje [30-32].

\section{Rezultatų vertinimas}

Visuose tyrimuose iki šių dienų buvo pastebètas reikšmingas apnèjos-hipopnejjos indekso (AHI) sumažèjimas 3 metus po implantacijos [33-38]. Sumažèjo pacientų mieguistumas, pagerejo nuotaika, gyvenimo ir miego kokybè [3,33-34, 36-39]. Pacientams, sergantiems miego apnèja, išjungus neurostimuliatorių nuo 5 dienų iki savaitès, AHI grịžo ị pradinį lygị [31,37]. N. hypoglossus stimuliacijos trūkumas - invazinè procedūra, kurios metu buvo nustatytas nedidelis šalutinis poveikis. Tai buvo su procedūra susijusios komplikacijos (tirpimas-skausmas-tinimas-infekcija pjūvio 
vietoje, liežuvio silpnumas), kurios ilgainiui išnyko; nuskausminamujjų ir(ar) antibiotikų terapijos sukeltos komplikacijos (liežuvio ịtrūkimai dèl trinties su dantimis, stimuliacijos sukeltas diskomfortas), kurios išnyko po adaptacijos. Sunkesnès nepageidaujamos reakcijos, tokios kaip infekcija incizijos vietoje, dèl kurios reikètų pašalinti neurostimuliatorių ar atlikti pakartotinę operaciją, siekiant repozicionuoti elektrodus ar prastai veikianti stimuliatorių, pasitaikè retai [33-35]. $N$. hypoglossus stimuliacijos veiksmingumas po 18 ir 36 mènesių išliko reikšmingas, kartu esant sumažèjusiam AHI bei pagerejjusiai gyvenimo ir miego kokybei. Po šio laiko nepageidaujamas šalutinis poveikis nustatytas retai $[36,39]$. Tyrimuose nedalyvavo sunkaus nutukimo laipsnio pacientai (KMI > 40), nes nustatyta, jog $n$. hypoglossus stimuliacija yra neefektyvi žmonèms su pernelyg padidejjusiu KMI $[34,35]$. Ši aplinkybė gali apriboti metodo taikymo galimybes, nes OMA pasireiškimas reikšmingai susijęs su antsvoriu [3].

\section{Išvados}

1. Nervus hypoglossus stimuliacija obstrukcinès miego apnejjos gydymui yra efektyvi esamųų terapijos metodų, tokių kaip CPAP ir viršutinių kvėpavimų takų operacijos, alternatyva, nes aprèpia anatominius ir neuromuskulinius ligos aspektus.

2. Individualūs kvejpavimo takų slègio parametrai miego metu, ryklès forma bei liežuvio dydis yra svarbūs kriterijai, atrenkant pacientus poliežuvinio nervo stimuliacijai.

3. Šiuo metu implantuojamos kelios skirtingos sistemos, atliekančios nervus hypoglossus stimuliaciją.

4. Nervus hypoglossus stimuliacijos rezultatai trejus metus buvo teigiami, nes pagerejo pacientu gyvenimo kokybé ir sumažèjo OMA sunkumo parametrai, tačiau procedūra gali sukelti nedidelị šalutinị poveikị ir negali būti taikoma smarkiai nutukusiems pacientams.

\section{Literatūra}

1. Franklin KA, Lindberg E. Obstructive sleep apnea is a common disorder in the population - a review on the epidemiology of sleep apnea. Journal Thoracic Disease 2015;7:1311-1322.

2. Sleep-related breathing disorders in adults: recommendations for syndrome definition and measurement techniques in clinical research. The report of an American academy of sleep medicine task force. Sleep 1999;22:667-89.

https://doi.org/10.1093/sleep/22.5.667

3. Peppard PE, Young T, Barnet JH, et al. Increased prevalence of sleep-disordered breathing in adults. American Journal Epidemiology 2013;177:1006-14.

https://doi.org/10.1093/aje/kws342

4. Strohl KP, Brown DB,Collop N, et al. An official American thoracic society clinical practice guideline: sleep apnea, sleepiness, and driving risk in noncommercial drivers. American Journal Respiratory Critical Care Medicine 2013;187(11):1259-1266. https://doi.org/10.1164/rccm.201304-0726ST

5. Marshall NS, Wong KK, Liu PY, Cullen SR, Knuiman MW, Grunstein RR. Sleep apnea as an independent risk factor for all - cause mortality: the Busselton health study. Sleep 2008;31(8):1079-1085.

6. Drager LF, Bortolotto LA, Figueiredo AC, Krieger EM, Lorenzi- Filho G. Effects of continuous positive airway pressure on early signs of atherosclerosis in obstructive sleep apnea. American Journal Respiratory Critical Care Medicine 2007; 176(7):706-712.

https://doi.org/10.1164/rccm.200703-500OC

7. Drager LF, Lopes HF, Maki-Nunes C, et al. The impact of obstructive sleep apnea on metabolic and inflammatory markers in consecutive patients with metabolic syndrome. Public Library Science 2010;5(8):e12065.

https://doi.org/10.1371/journal.pone.0012065

8. Drager LF, Togeiro SM, Polotsky VY, Lorenzi-Filho G. Obstructive sleep apnea: a cardiometabolic risk in obesity and the metabolic syndrome. Journal American College Cardiology 2013;62(7):569-576.

https://doi.org/10.1016/j.jacc.2013.05.045

9. Nieto FJ, Peppard PE, Young T, Finn L, Hla KM, Farre R. Sleep disordered breathing and cancer mortality: results from the Wisconsin sleep cohort study. American Respiratory Critical Care Medicine 2012;186(2):190-194.

https://doi.org/10.1164/rccm.201201-0130OC

10. Peppard PE, Young T, Palta M, Skatrud J. Prospective study of the association between sleep-disordered breathing and hypertension. The New England Journal Medicine 2000;342(19):1378-1384.

https://doi.org/10.1056/NEJM200005113421901

11. Yaffe K, Laffan AM, Harrison SL, et al. Sleep-disordered breathing, hypoxia, and risk of mild cognitive impairment and dementia in older women. Journal American Medical Association 2011;306(6):613-619.

https://doi.org/10.1001/jama.2011.1115

12. Gay P, Weaver T, Loube D, Iber C. Evaluation of positive airway pressure treatment for sleep related breathing disorders in adults. Sleep 2006;29(3):381-401.

https://doi.org/10.1093/sleep/29.3.381

13. Sawyer AM, Gooneratne NS, Marcus CL, Ofer D, Richards $\mathrm{KC}$, Weaver TE. A systematic review of CPAP adherence across age groups: clinical and empiric insights for developing CPAP adherence interventions. Sleep Medicine Reviews 2011;15(6):343-356.

https://doi.org/10.1016/j.smrv.2011.01.003

14. Engleman HM, Wild MR. Improving CPAP use by patients with the sleep apnoea/hypopnoea syndrome (SAHS). Sleep Medicine Reviews 2003;7(1):81-99.

https://doi.org/10.1053/smrv.2001.0197 
15. Spicuzza L, Caruso D, Di Maria G. Obstructive sleep apnoea syndrome and its management. Therapeutic Advances in Chronic Disease 2015;6(5): 273-285. https://doi.org/10.1177/2040622315590318

16. Dempsey JA, Veasey SC, Morgan BJ, O'Donnell CP. Pathophysiology of sleep apnea. Physiological Reviews 2010;90:47-112. https://doi.org/10.1152/physrev.00043.2008

17. White DP. Pathogenesis of obstructive and central sleep apnea. American Journal Respiratory Critical Care Medicine 2005;172:1363-70.

https://doi.org/10.1164/rccm.200412-1631SO

18. Berkovitz B, Holland GR, Moxham BJ. Regional topography of the mouth and related areas. Oral anatomy, histology and embryology. Elsevier 2018:70-91.

19. Mezzanotte WS, Tangel DJ, White DP. Waking genioglossal electromyogram in sleep apnea patients versus normal controls (a neuromuscular compensatory mechanism). Journal Clinical Investigation 1992;89:1571-9.

https://doi.org/10.1172/JCI115751

20. Onal E, Lopata M, O'Connor TD. Diaphragmatic and genioglossal electromyogram responses to $\mathrm{CO} 2$ rebreathing in humans. Journal Applied Physiology 1981;50(5):1052-1055. https://doi.org/10.1152/jappl.1981.50.5.1052

21. Olson LG, Fouke JM, Hoekje PL, Strohl KP. A biomedical view of upper airway function. In: Mathew OP, Sant'Ambrogio G, eds. Respiratory Function of the Upper Airway. New York, NY: Marcel Dekker 1988:35:359-389.

22. Ragab S. Hypoglossal nerve conduction studies in patients with obstructive sleep apnea. Egypt Journal Otolaryngology 2013;29:176-81.

23. Worsnop CJ, Kay A, Pierce R, Kim Y, Trinder J. Journal activity of respiratory pump and upper airway muscles during sleep onset. Journal Applied Physiology 1998; 85: 908-920. https://doi.org/10.1152/jappl.1998.85.3.908

24. Cori JM, O'Donoghue FJ, Jordan AS. Sleeping tongue: current perspectives of genioglossus control in healthy individuals and patients with obstructive sleep apnea. Nature Science Sleep 2018,10,169-179.

https://doi.org/10.2147/NSS.S143296

25. White DP. Pathogenesis of obstructive and central sleep apnea. American Journal Respiratory Critical Care Medicine 2005;172:1363-70.

https://doi.org/10.1164/rccm.200412-1631SO

26. Strohl KP, Baskin J, Lance C, et al. Origins of and implementation concepts for upper airway stimulation therapy for obstructive sleep apnea. Respir Investigation 2016;54(4):241-249. https://doi.org/10.1016/j.resinv.2016.01.006

27. Schwartz AR, Eisele DW, Hari A, Testerman R, Erickson D, Smith PL. Electrical stimulation of the lingual musculature in obstructive sleep apnea. Journal Applied Physiology 1996;81(2):643-652. https://doi.org/10.1152/jappl.1996.81.2.643

28. Gold AR, Schwartz AR. The pharyngeal critical pressure. The whys and hows of using nasal continuous positive airway pressure diagnostically. Chest 1996;110(4):1077-1088.

https://doi.org/10.1378/chest.110.4.1077

29. Curado TF, Oliven A, Sennes LU, Polotsky VY, Eisele D, Schwartz AR. Neurostimulation treatment of OSA. Chest 2018;154(6):1435-1447.

https://doi.org/10.1016/j.chest.2018.08.1070

30. Eisele DW, Smith PL, Alam DS, Schwartz AR. Direct hypoglossal nerve stimulation in obstructive sleep apnea. Archives Otolaryngology-Head Neck Surgery 1997;123(1):57-61. https://doi.org/10.1001/archotol.1997.01900010067009

31. Strollo PJ, Soose RJ, Maurer JT, et al. Upper-airway stimulation for obstructive sleep apnea. The New England Journal of Medicine 2014;370(2):139-149. https://doi.org/10.1056/NEJMoa1308659

32. Zaidi FN, Meadows P, Jacobowitz O, Davidson TM. Tongue anatomy and physiology, the scientific basis for a novel targeted neurostimulation system designed for the treatment of obstructive sleep apnea. Neuromodulation 2013;16(4):376-386. https://doi.org/10.1111/j.1525-1403.2012.00514.x

33. Eastwood PR, Barnes M, Walsh JH, et al. Treating obstructive sleep apnea with hypoglossal nerve stimulation. Sleep 2011;34:1479-86.

https://doi.org/10.5665/sleep. 1380

34. Kezirian EJ, Goding GS, Malhotra A, et al. Hypoglossal nerve stimulation improves obstructive sleep apnea: 12-month outcomes. Journal Sleep Research 2014; 23:77-83.

https://doi.org/10.1111/jsr.12079

35. Van de Heyning PH, Badr MS, Baskin JZ, et al. Implanted upper airway stimulation device for obstructive sleep apnea. Laryngoscope 2012;122:1626-33.

https://doi.org/10.1002/lary.23301

36. Strollo PJ, Gillespie MB, Soose RJ, et al. Upper airway stimulation for obstructive sleep apnea: durability of the treatment effect at 18 months. Sleep 2015;38:593-8.

https://doi.org/10.5665/sleep.5054

37. Woodson BT, Gillespie MB, Soose RJ, et al. Randomized controlled withdrawal study of upper airway stimulation on OSA: short-and long-term effect. Otolaryngol Head Neck Surgery 2014;151:880-7. https://doi.org/10.1177/0194599814544445

38. Soose RJ, Woodson BT, Gillespie MB, et al. Upper airway stimulation for obstructive sleep apnea: self-reported outcomes at 24 months. Journal Clinical Sleep Medicine 2016;12(1):43-8. https://doi.org/10.5664/jcsm.5390

39. Woodson BT, Soose RJ, Gillespie MB, et al. Three-year outcomes of cranial nerve stimulation for obstructive sleep apnea: the STAR trial. Otolaryngol Head Neck Surgery 2016;154(1):181-188. 


\section{4}

https://doi.org/10.1177/0194599815616618

40. Leiter JC. Upper airway shape: is it important in the pathogenesis of obstructive sleep apnea? American Journal Respiratory and Critical Care Medicine 1996;153(3):894-898.

https://doi.org/10.1164/ajrccm.153.3.8630569

41. Schwab RJ, Wang SH, Verbraecken J, et al. Anatomic predictors of response and mechanism of action of upper airway stimulation therapy in patients with obstructive sleep apnea. Sleep 2018;41(4).

https://doi.org/10.1093/sleep/zsy021

HYPOGLOSSAL NERVE STIMULATION FOR THE TREATMENT OF OBSTRUCTIVE SLEEP APNEA

L. Sereikaitė, M. Jasinskaitė, S. Stiklioraitis, Ž. Undzėnaitė

Keywords: nervus hypoglossus stimulation, obstructive sleep
Summary

Obstructive sleep apnea (OSA) is a clinical condition that poses a significant threat to both personal and public health. Continuous positive airway pressure (CPAP) remains the main treatment method for this pathology and yields positive results, although inadequate usage lowers its efficiency, and while various alternatives such as upper airway surgical procedures are widely used, they target only the anatomic component of OSA. Over the last few decades, many clinical trials have shown promising results of hypoglossal nerve stimulation (HNS) being a viable treatment option for this disease, having improved both objective and subjective measurements of the severity of OSA, as it tackles anatomic as well as neuromuscular aspects of the pathology.

Correspondence to: liveta.sereikaite@gmail.com

Gauta 2020-03-11

apnea. 